\section{FIRST FULLY DDA COMPLIANT FACILITY IN MANCHESTER}

The Withington Dental Care Centre is the first fully Disability Discrimination Act (DDA) compliant facility in Manchester to offer equal access to compre-

hensive dental care, including the use of inhalation sedation, for wheelchair users and bariatric patients.

One surgery provides a customised

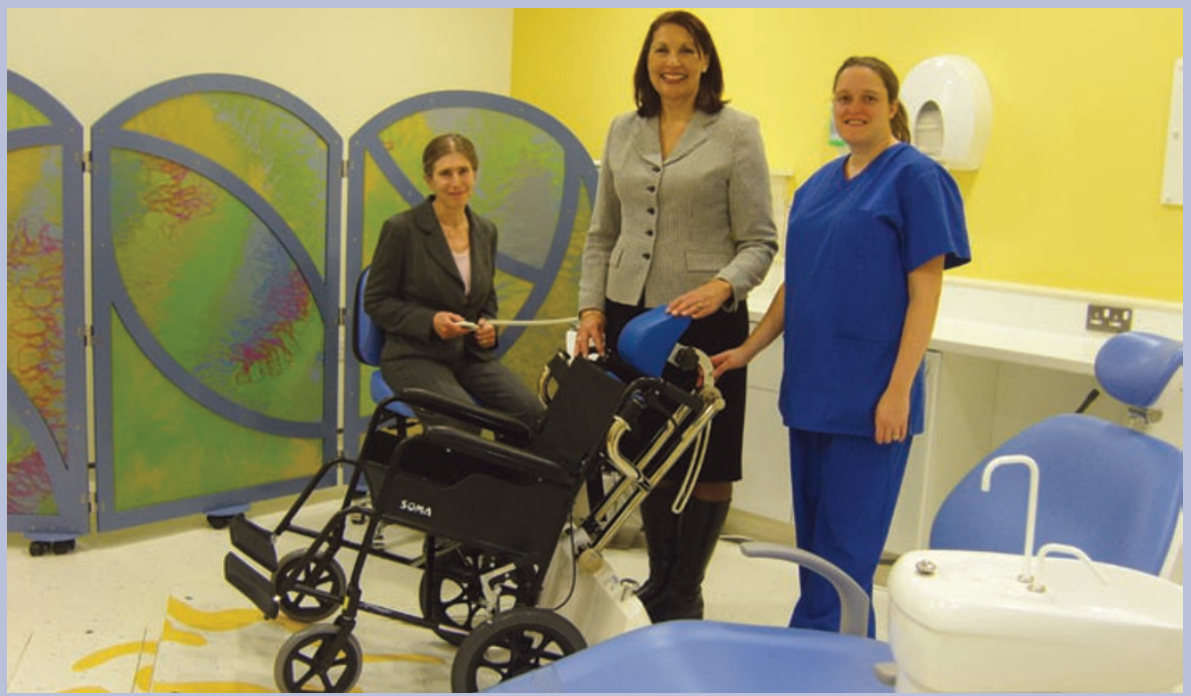

Left to right: Jane Leahy - Specialist in Special Care Dentistry, Cheryl Rivkin - Clinical Director, Manchester PCT Dental Service and Joanne Walters - Dental Nurse at the new Withington Dental Care Centre wheelchair recliner workstation which will enable patients to receive the full spectrum of dental care while reclined in their wheelchair. A fixed ceiling hoist in the second surgery enables patients who are unable or unwilling to recline in their wheelchair to be transferred to an easy access dental chair. There is also a bariatric plinth for patients who are unable to use a conventional dental chair.

The Centre also provides digital X-ray facilities for wheelchair users and caters for a full range of additional needs such as visual and hearing impairment.

'It has been an exciting project to work on with the involvement of a large enthusiastic and committed team and we are delighted with the result,' said Cheryl Rivkin, Clinical Director of the Manchester PCT Dental Service.

A key feature of the new centre is its eye-catching artwork and includes themed flooring, back-lit artwork and clever use of colour to create a userfriendly environment. 